\title{
On pure-strategy Nash equilibria in price-quantity games
}

Citation for published version (APA):

Bos, I., \& Vermeulen, A. J. (2015). On pure-strategy Nash equilibria in price-quantity games. Maastricht University, Graduate School of Business and Economics. GSBE Research Memoranda No. 018 https://doi.org/10.26481/umagsb.2015018

Document status and date:

Published: 01/01/2015

DOI:

10.26481/umagsb.2015018

Document Version:

Publisher's PDF, also known as Version of record

\section{Please check the document version of this publication:}

- A submitted manuscript is the version of the article upon submission and before peer-review. There can be important differences between the submitted version and the official published version of record.

People interested in the research are advised to contact the author for the final version of the publication, or visit the DOI to the publisher's website.

- The final author version and the galley proof are versions of the publication after peer review.

- The final published version features the final layout of the paper including the volume, issue and page numbers.

Link to publication

\footnotetext{
General rights rights.

- You may freely distribute the URL identifying the publication in the public portal. please follow below link for the End User Agreement:

www.umlib.nl/taverne-license

Take down policy

If you believe that this document breaches copyright please contact us at:

repository@maastrichtuniversity.nl

providing details and we will investigate your claim.
}

Copyright and moral rights for the publications made accessible in the public portal are retained by the authors and/or other copyright owners and it is a condition of accessing publications that users recognise and abide by the legal requirements associated with these

- Users may download and print one copy of any publication from the public portal for the purpose of private study or research.

- You may not further distribute the material or use it for any profit-making activity or commercial gain

If the publication is distributed under the terms of Article $25 \mathrm{fa}$ of the Dutch Copyright Act, indicated by the "Taverne" license above, 


\section{Maastricht University}

Iwan Bos, Dries Vermeulen

On Pure-Strategy Nash

Equilibria in Price-Quantity Games

$\mathrm{RM} / 15 / 018$

\section{GSBE}

Maastricht University School of Business and Economics

Graduate School of Business and Economics

P.O Box 616

NL-6200 MD Maastricht

The Netherlands 


\title{
On Pure-Strategy Nash Equilibria \\ in Price-Quantity Games
}

\author{
Iwan Bos* Dries Vermeulen ${ }^{\dagger}$
}

May 27, 2015

\begin{abstract}
This paper examines the existence and characteristics of pure-strategy Nash equilibria in oligopoly models in which firms set both prices and quantities. Existence is proved for a broad and natural class of price-quantity games. With differentiated products, the equilibrium outcome is similar to that of a price-only model. With undifferentiated products and limited spillover demand, there are rationing equilibria in which combined production falls short of market demand. Moreover, there might again be an equilibrium reflecting the outcome of a price game. Competition in price and quantity may thus yield Bertrand outcomes under a variety of market conditions.
\end{abstract}

Keywords: Bertrand Oligopoly; Bertrand-Edgeworth Competition; Cournot Oligopoly; Oligopoly Theory; Price-Quantity Competition.

JEL Codes: D4; L1.

*Department of Organization \& Strategy, Maastricht University. Corresponding author at: P.O. Box 616, 6200 MD Maastricht, The Netherlands. E-mail: i.bos@maastrichtuniversity.nl.

${ }^{\dagger}$ Department of Quantitative Economics, Maastricht University. 


\section{Introduction}

Imagine a remote village with two bakeries baking breads that are close substitutes in the eyes of the villagers. If this was a 'Cournot market', then both bakers would decide how much bread to bake and bring to the marketplace. An auctioneer would be waiting there to set the price in such a way that market demand equals the total amount offered. If, instead, this was a 'Bertrand market', then each bakery would set its selling price and wait for customers. After the realization of demand, both would be obliged to bake exactly the amount of bread their clients were asking for. A glance at reality shows, however, that such a bread market is neither a Cournot nor a Bertrand market. ${ }^{1}$ It is not a Cournot market as bakeries commonly choose their own prices, but it is not a Bertrand market either as it is usually up to the bakers to decide how much bread to make. More generally, in free-market societies there typically is no law telling firms how much to supply and what price to charge. ${ }^{2}$

A natural assumption in theories of oligopoly would therefore be that firms choose both their price and quantity of output. The foundation for this type of analysis is due to Francis Edgeworth $(1922,1925){ }^{3}$ He recognized that price-setting oligopolists may be unable or unwilling to meet their demand. For example, an undertaking might not be able to generate sufficient supplies when there is a shortage and it is already producing at capacity. Similarly, it can be de facto capacity-constrained when production precedes sales and cannot be boosted instantly. Also, even when a firm has the ability, it will lack the will to satisfy all its customers when demand exceeds its 'competitive supply'. ${ }^{4}$ As is well-known, the disturbing conclusion of Edgeworth's explorations was that oligopoly prices are essentially indeterminate. In more modern language, we would say that no pure-strategy Nash equilibrium exists. This nonexistence problem received much attention ever since and has been demonstrated in a variety of settings where firms compete in prices and quantities.

It is often conjectured that the non-existence problem is, at least in part, driven by the frequently used 'homogeneous goods assumption' as it gives rise to discontinuities in demand. In fact, Edgeworth himself hypothesized the degree of indeterminateness to diminish with an increase in product differentiation. ${ }^{5}$ Assuming imperfect substitutes does, however, not generally yield a solution. Price-quantity games with heterogeneous products have been studied by Shapley and Shubik (1969), Alger (1979), Friedman (1988), Benassy (1989) and

\footnotetext{
${ }^{1}$ For a detailed discussion of classical models of oligopoly, see Vives (1999).

${ }^{2}$ Evidently, there may be regulated markets, but these are the exception rather than the rule.

${ }^{3}$ The original version of his 1925-paper dates back to 1897 .

${ }^{4}$ This may occur when firms' cost functions exhibit decreasing returns to scale. Edgeworth (1922) studies the case of quadratic costs, whereas capacity constraints are considered in Edgeworth (1925).

${ }^{5}$ See Edgeworth (1925, p. 121).
} 
Canoy (1996). Under a variety of cost and demand conditions, all establish that the problem of non-existence remains for industries with a few firms selling sufficiently close substitutes. In this paper, we re-examine price-quantity competition in oligopolies. ${ }^{6}$ Specifically, our purpose is to shed light on the non-existence problem by presenting conditions under which a pure-strategy equilibrium does exist. We consider price-quantity games with continuous as well as discontinuous demand in terms of the own prices. The first is characteristic for differentiated goods, whereas the second applies to perfect substitutes. For both cases, we provide a broad and natural class of price-quantity games with a pure-strategy equilibrium.

Additionally, we are able to characterize these equilibria. With differentiated products, the equilibrium is shown to be similar to that of a basic Bertrand model. Moreover, and contrary to previous findings, its existence need not directly depend on the number of firms or the degree of differentiation. With discontinuous demand, equilibria come in two types. First, there is a range of rationing equilibria in which combined production falls short of market demand. This result is surprising as it has long been argued that the competitive outcome would be the only equilibrium candidate. ${ }^{7}$ Although we do find that firms in equilibrium price at marginal costs, these prices are typically too low to ensure saturation of the market. Second, there may again be an equilibrium reflecting the outcome of a price-only model. Therefore, our analysis additionally provides some foundation for Bertrand price models.

The non-existence problem pertains to pure-strategy Nash equilibria. Mixed-strategy equilibria have been repeatedly shown to exist under a variety of assumptions. ${ }^{8}$ Mixed equilibria are, however, problematic within this context for at least two reasons. Perhaps the most prominent problem is simply that it is at odds with reality. Indeed, butchers, brewers or bakers typically do not roll dice to determine their prices or quantities of output. This is especially cumbersome when considering repeated interaction among firms. ${ }^{9}$ Another issue is that models of oligopoly become significantly more complicated when allowing for random

\footnotetext{
${ }^{6}$ Regarding price-quantity models, it is not uncommon in the literature to distinguish between, on the one hand, 'production to order' or 'Bertrand-Edgeworth competition' and, on the other hand, 'production in advance' (see, e.g., Shubik (1955, 1960), Maskin (1986) or Tasnádi (2004)). In case of the former, production takes place after the realization of demand, whereas in case of the latter production precedes sales. All results derived in this paper apply equally well to both cases.

${ }^{7}$ See the pioneering works of Shubik $(1955,1960)$ and, in particular, Theorem 2 in Shubik $(1960$, p. 100).

${ }^{8}$ See, among others, Levitan and Shubik (1972), Dixon (1984), Gertner (1986), Maskin (1986) and Tasnádi (2004).

${ }^{9}$ In this regard, Friedman (1988, p. 608) stated that:

". . . a deep understanding of oligopolistic behavior cannot be achieved by means of singleperiod models with results that are unreasonable in a multiperiod setting. This article is intended as a prelude to the study of dynamic models. Mixed strategies, under which prices and outputs are randomly selected in each period, seem bizarre in an infinite-horizon oligopoly."
} 
strategies. In particular, it is often difficult to provide an explicit characterization of mixedstrategy equilibria. As such, this concept is of limited use in applied research on oligopolistic industries.

The next section gives a general outline of the model and offers some preliminary insights that serve as a basis for the ensuing study. The main analysis and results are presented in Sections 3 and 4 . Section 3 considers price-quantity competition with continuous demand, whereas the discontinuous demand case is described in Section 4. A few illustrative examples are presented in Section 5. Section 6 concludes.

\section{A Model of Price-Quantity Competition}

In this section, we lay out the basics of our price-quantity oligopoly model. It is assumed there are $n \geq 2$ profit-maximizing firms where the set of firms is $N=\{1, \ldots, n\}$. Each firm $i \in N$ simultaneously picks a price-quantity pair $\left(p_{i}, q_{i}\right)$, with $p_{i} \geq 0$ and $q_{i} \geq 0$. Let the vector of prices and quantities be respectively given by $p=\left(p_{1}, \ldots, p_{n}\right)$ and $q=\left(q_{1}, \ldots, q_{n}\right)$. Moreover, $p_{-i}=\left(p_{j}\right)_{j \neq i}$ and $q_{-i}=\left(q_{j}\right)_{j \neq i}$. Given the price-quantity choices of competitors, demand for the products of firm $i$ is denoted $D_{i}\left(p_{i}, p_{-i}, q_{-i}\right)$. Firm $i$ 's cost of production is given by $C_{i}\left(q_{i}\right)$, which is a strictly increasing continuous function of its own output $q_{i}$ and $C_{i}(0)=0$. Both the demand and cost structure will be further specified below.

The firm's objective is then to pick a profit-maximizing price-quantity pair:

$$
\max _{p_{i}, q_{i}} \Pi_{i}(p, q)=p_{i} \cdot s_{i}(p, q)-C_{i}\left(q_{i}\right), \forall i \in N,
$$

where $s_{i}(p, q)$ denotes firm $i$ 's sales. It is clear that a firm cannot offer more than it produces and cannot sell more than is demanded. Therefore, sales equals the minimum of production and demand: ${ }^{10}$

$$
s_{i}(p, q)=\min \left\{q_{i}, D_{i}\left(p_{i}, p_{-i}, q_{-i}\right)\right\} .
$$

A price-quantity pair $\left(p_{i}, q_{i}\right)$ is firm $i$ 's best response to $\left(p_{-i}, q_{-i}\right)$ when for each choice $\left(\tilde{p}_{i}, \tilde{q}_{i}\right)$ it holds that

$$
\Pi_{i}\left(p_{i}, q_{i}, p_{-i}, q_{-i}\right) \geq \Pi_{i}\left(\tilde{p}_{i}, \tilde{q}_{i}, p_{-i}, q_{-i}\right) .
$$

The above specifications are sufficient to show the following useful result stating that none of the firms find it optimal to produce in excess of demand.

\footnotetext{
${ }^{10}$ Note that, due to the profit-maximizing assumption, firms bring all produced quantities to the market. Additionally, they will not produce more than the profit-maximizing output at the price set. This condition, albeit more general, therefore effectively coincides with the voluntary-trading constraint in standard BertrandEdgeworth settings.
} 
Lemma 1. For each firm $i \in N$, all strategies $\left(p_{i}, q_{i}\right)$ for which $q_{i}>D_{i}\left(p, q_{-i}\right)$ are strictly dominated.

Proof Suppose that $\left(p_{i}, q_{i}\right)$ is a best response of firm $i$ to $\left(p_{-i}, q_{-i}\right)$ and suppose further that $q_{i}>D_{i}\left(p, q_{-i}\right)$. Since $s_{i}=\min \left\{q_{i}, D_{i}\left(p, q_{-i}\right)\right\}$, it holds that $s_{i}=D_{i}\left(p, q_{-i}\right)$. Now define

$$
\tilde{q}_{i}=\frac{q_{i}+D_{i}\left(p, q_{-i}\right)}{2} .
$$

As $C_{i}$ is continuous and strictly increasing, it follows that $C_{i}\left(q_{i}\right)>C_{i}\left(\tilde{q}_{i}\right)$. Combining with $s_{i}=D_{i}\left(p, q_{-i}\right)$, this implies

$$
\Pi_{i}\left(p_{i}, q_{i}, p_{-i}, q_{-i}\right)<\Pi_{i}\left(p_{i}, \tilde{q}_{i}, p_{-i}, q_{-i}\right)
$$

which contradicts the assumption of $\left(p_{i}, q_{i}\right)$ being a best response.

In light of the purpose of this study, we restrict ourselves in the following to pure-strategy Nash equilibria. A vector of choices $(p, q)$ is an equilibrium when for all $i \in N$ and each choice $\left(\tilde{p}_{i}, \tilde{q}_{i}\right)$ it holds that

$$
\Pi_{i}\left(p_{i}, q_{i}, p_{-i}, q_{-i}\right) \geq \Pi_{i}\left(\tilde{p}_{i}, \tilde{q}_{i}, p_{-i}, q_{-i}\right) .
$$

Lemma 1 excludes the possibility that in equilibrium a firm operates above its demand curve. As will become clear in the ensuing analysis, and depending on the specifics of the model, the two other types of outcome might occur in equilibrium. Akin to the Bertrand model, all firms may choose to meet their demand at the price set. Alternatively, one or more firms may find it optimal to satisfy only part of their customers. To indicate these possibilities, we will use the following definitions:

- An equilibrium $\left(p^{*}, q^{*}\right)$ is a Bertrand equilibrium when $q_{i}=D_{i}\left(p, q_{-i}\right)$ for all $i \in N$.

- An equilibrium $\left(p^{*}, q^{*}\right)$ is a rationing equilibrium when $q_{i} \leq D_{i}\left(p, q_{-i}\right)$ for all $i \in N$ and $q_{j}<D_{j}\left(p, q_{-j}\right)$ for at least one firm $j$.

\section{Price-Quantity Competition with Continuous Demand}

Let us begin by considering price-quantity competition with differentiated products. If goods are less than perfect substitutes, firms typically do not lose their entire clientele when setting their price just above that of the competition. In a similar vein, slightly undercutting rivals' prices is unlikely to yield the market. To capture this idea that 'small changes should have small effects', it is natural to think of demand as a continuous function of prices. Hotelling (1929, p. 44) formulated this as follows: 
“...a discontinuity, like a vacuum, is abhorred by nature. More typical of real situations is the case in which the quantity sold by each merchant is a continuous function of two variables, his own price and his competitor's. Quite commonly, a tiny increase in price by one seller will send only a few customers to the other."

To formalize, suppose there exists a function $E_{i}$ such that $D_{i}\left(p, q_{-i}\right)=\max \left\{E_{i}\left(p, q_{-i}\right), 0\right\}$. We start by making the following assumptions on demand and cost.

For all $\left(p_{-i}, q_{-i}\right)$ and $i \in N$ :

A1 $E_{i}$ is continuous and strictly decreasing in $p_{i}$.

A2 $\exists \varepsilon, \eta>0$ such that $\forall q_{i} \in(0, \eta), \frac{C_{i}\left(q_{i}\right)}{q_{i}}<\varepsilon$ and $D_{i}\left(\varepsilon, p_{-i}, q_{-i}\right)>0$.

A1 reflects the law of demand for firm $i$ 's product, whereas A2 ensures that firms have an incentive to be productive. Because both price and quantity are decision variables, it is in principle possible that production and demand do not coincide. It follows from Lemma 1, however, that overproduction will not occur in equilibrium. As the next result shows, the properties A1 and A2 are sufficient to show that, in equilibrium, shortages will not occur either.

Lemma 2. Under A1-A2, all equilibria are Bertrand equilibria.

Proof Suppose that $\left(p_{i}, q_{i}\right)$ is a best reply of firm $i$ to $\left(p_{-i}, q_{-i}\right)$. For an equilibrium to be a Bertrand equilibrium it must hold that $q_{i}=D_{i}\left(p, q_{-i}\right)$ for all $i \in N$. By Lemma 1 , we know that $q_{i}>D_{i}\left(p, q_{-i}\right)$ cannot occur in equilibrium. Therefore, it remains to be shown that $q_{i}<D_{i}\left(p, q_{-i}\right)$ cannot occur either. Towards that end, we assume $q_{i}<D_{i}\left(p, q_{-i}\right)$ and derive a contradiction.

First, note that all strategies with $q_{i}=0$ are strictly dominated. By A2, there exists a price $\tilde{p}_{i}>0$ such that $D_{i}\left(\tilde{p}_{i}, p_{-i}, q_{-i}\right)>0$. Given this price $\tilde{p}_{i}$, and again by A2, there exists a $\tilde{q}_{i}>0$ such that $\frac{C_{i}\left(\tilde{q}_{i}\right)}{\tilde{q}_{i}}<\tilde{p}_{i}$. Thus, $\Pi_{i}\left(\tilde{p}_{i}, \tilde{q}_{i}, p_{-i}, q_{-i}\right)>0$, whereas all strategies with $q_{i}=0$ yield zero profit. We conclude that $q_{i}=0$ cannot occur in equilibrium.

Next, suppose that $0<q_{i}<D_{i}\left(p, q_{-i}\right)$. By A1, there exists a $\varepsilon>0$ such that for $\tilde{p}_{i}=p_{i}+\varepsilon$ it still holds that $q_{i}<D_{i}\left(\tilde{p}_{i}, p_{-i}, q_{-i}\right)$. However, this implies

$$
\Pi_{i}\left(\tilde{p}_{i}, q_{i}, p_{-i}, q_{-i}\right)=\tilde{p}_{i} \cdot q_{i}-C_{i}\left(q_{i}\right)>p_{i} \cdot q_{i}-C_{i}\left(q_{i}\right)=\Pi_{i}\left(p_{i}, q_{i}, p_{-i}, q_{-i}\right),
$$

which contradicts $\left(p_{i}, q_{i}\right)$ being a best reply of firm $i$ to $\left(p_{-i}, q_{-i}\right)$. We conclude that in equilibrium it must hold that $q_{i}=D_{i}\left(p, q_{-i}\right)$, for all $i \in N$. 
Thus, firms have a strict preference for price-quantity pairs on their demand curve; a finding that appears to be very robust. Indeed, it has repeatedly been found to hold under a variety of mild conditions. ${ }^{11}$ Though this result greatly reduces the number of equilibrium candidates, it is commonly taken as a basis for establishing non-existence of an equilibrium. In contrast, we will use it as a foundation for proving existence. Together with assumption A2, the following three conditions are shown to be sufficient.

For all $\left(p_{-i}, q_{-i}\right)$ and $i \in N$ :

B1 $E_{i}$ is continuously differentiable and strictly decreasing in $p_{i}$. Moreover, $\exists \xi>0$ such that $\frac{\partial E_{i}}{\partial p_{i}} \leq-\xi<0$.

B2 $\exists K>0$ such that $\sum_{i \in N} D_{i}\left(p, q_{-i}\right) \leq K$.

B3 At all $q_{i}>0, C_{i}\left(q_{i}\right)$ is continuously differentiable and $C_{i}^{\prime}\left(q_{i}\right)$ is non-decreasing.

$\mathrm{B} 1$ is similar to $\mathrm{A} 1$, but adds the requirement that $E_{i}$ is differentiable with respect to the own price and that this derivative is bounded away from zero. B2 states that market demand is bounded and B3 imposes some structure on production technologies. Specifically, the cost functions are assumed to exhibit constant or decreasing returns to scale.

Theorem 3. Under A2 and B1-B3, there exists at least one equilibrium.

Proof By Lemma 2, we know that in equilibrium each firm $i \in N$ will pick a price-quantity pair on its demand curve. Thus, for a given vector $\left(p_{-i}, q_{-i}\right)$, a best reply $\left(p_{i}^{*}, q_{i}^{*}\right)$ of firm $i$ to $\left(p_{-i}, q_{-i}\right)$ satisfies $q_{i}^{*}=D_{i}\left(p_{i}^{*}, p_{-i}, q_{-i}\right)$. It follows that $\left(p_{i}^{*}, q_{i}^{*}\right)$ is a best response to $\left(p_{-i}, q_{-i}\right)$ precisely when $p_{i}^{*}$ maximizes

$$
R_{i}\left(p_{i}\right):=p_{i} \cdot D_{i}\left(p_{i}, p_{-i}, q_{-i}\right)-C_{i}\left(D_{i}\left(p_{i}, p_{-i}, q_{-i}\right)\right)
$$

and $q_{i}^{*}=D_{i}\left(p_{i}^{*}, p_{-i}, q_{-i}\right)$. Using this fact, we now proceed in three steps to prove existence of a pure-strategy Nash equilibrium.

Step 1. We show that there is a unique price $p_{i}^{*}>0$ that maximizes $R_{i}$.

To begin, notice that $p_{i}=0$ does not maximize $R_{i}\left(p_{i}\right)$. By A2, there exists a $\tilde{p}_{i}>0$ such that $D_{i}\left(\tilde{p}_{i}, p_{-i}, q_{-i}\right)>0$. Therefore, $D_{i}=E_{i}$ and a price that maximizes $R_{i}$ is strictly positive, equating marginal revenue with marginal cost:

$$
E_{i}+p_{i} \cdot \frac{\partial E_{i}}{\partial p_{i}}-\frac{d C_{i}}{d q_{i}} \cdot \frac{\partial E_{i}}{\partial p_{i}}=0
$$

\footnotetext{
${ }^{11}$ See, for instance, Alger (1979, Theorem 3.1), Friedman (1988, Lemma 3), Benassy (1989, Theorem 1) and Canoy (1996, Lemma 1). In the context of an evolutionary model, Khan and Peeters (2015) have recently shown that this outcome may also result from firms imitating the most profitable producer.
} 
Rearranging gives

$$
E_{i}=\frac{\partial E_{i}}{\partial p_{i}} \cdot\left[\frac{d C_{i}}{d q_{i}}-p_{i}\right]
$$

We now compare the LHS of (2) with the RHS. Define $A_{i}\left(p_{i}\right)=E_{i}\left(p_{i}, p_{-i}, q_{-i}\right)$. By B1 and A2, we know that $A_{i}(0)>0$. Moreover, by $\mathrm{B} 1$ we know that $A_{i}$ is strictly decreasing and $A_{i}\left(p_{i}\right) \leq E_{i}\left(0, p_{-i}, q_{-i}\right)-\xi \cdot p_{i}$.

We now analyze the RHS of (2). Define

$$
F_{i}\left(p_{i}\right)=\frac{\partial E_{i}}{\partial p_{i}} \cdot\left[\frac{d C_{i}}{d q_{i}}\left(E_{i}\left(p_{i}, p_{-i}, q_{-i}\right)\right)-p_{i}\right] .
$$

Let us first have a closer look at the part between square brackets.

$$
B_{i}\left(p_{i}\right)=\frac{d C_{i}}{d q_{i}}\left(E_{i}\left(p_{i}, p_{-i}, q_{-i}\right)\right)-p_{i}
$$

Since $E_{i}$ is strictly decreasing in $p_{i}$ by B1 and costs are weakly convex by B3, it follows that

$$
p_{i} \mapsto \frac{d C_{i}}{d q_{i}}\left(E_{i}\left(p_{i}, p_{-i}, q_{-i}\right)\right)
$$

is strictly positive and non-increasing. Consequently, there is a unique $p_{i}^{m}>0$ with

$$
\frac{d C_{i}}{d q_{i}}\left(E_{i}\left(p_{i}^{m}, p_{-i}, q_{-i}\right)\right)=p_{i}^{m} .
$$

Next, note that the function $B_{i}\left(p_{i}\right)$ is negative and strictly decreasing for $p_{i}>p_{i}^{m}$. Thus, as $\frac{\partial E_{i}}{\partial p_{i}}$ is negative and strictly decreasing by B1, $F_{i}$ is positive and strictly increasing for $p_{i}>p_{i}^{m}$. Furthermore, $F_{i}\left(p_{i}^{m}\right)=0$.

Finally, combining the observations on $A_{i}$ and $F_{i}$, there is a unique $p_{i}^{*}>p_{i}^{m}>0$ with $A_{i}\left(p_{i}^{*}\right)=F_{i}\left(p_{i}^{*}\right)$. Since $\frac{d R_{i}}{d p_{i}}=A_{i}-F_{i}, \frac{d R_{i}}{d p_{i}}\left(p_{i}^{*}\right)=0$. Moreover, $\frac{d R_{i}}{d p_{i}}\left(p_{i}\right)>0$ for $p_{i}<p_{i}^{*}$ and $\frac{d R_{i}}{d p_{i}}\left(p_{i}\right)<0$ for $p_{i}>p_{i}^{*}$. We conclude that $p_{i}^{*}$ is the unique maximizer of $R_{i}$.

For each firm $i \in N$ and a given choice vector $(p, q)$, we can now define $f_{i}(p, q):=p_{i}^{*}$. Before proceeding, let us define a function $H: \mathbb{R}_{+}^{2 n} \rightarrow \mathbb{R}_{+}^{2 n}$ for each choice vector $(p, q) \in \mathbb{R}_{+}^{2 n}$ :

$$
H(p, q)=\left(f_{1}(p, q), \ldots, f_{n}(p, q), D_{1}\left(p, q_{-1}\right), \ldots, D_{n}\left(p, q_{-n}\right)\right) .
$$

Step 2. We show that there is a point $\left(p^{*}, q^{*}\right)$ with $H\left(p^{*}, q^{*}\right)=\left(p^{*}, q^{*}\right)$. By $\mathrm{A} 2$ and $\mathrm{B} 2$, we know that $E_{i}\left(0, p_{-i}, q_{-i}\right) \leq K$. Using B1, it follows that

$$
E_{i}\left(p_{i}, p_{-i}, q_{-i}\right) \leq K+\xi \cdot p_{i}
$$

Therefore, $0 \leq p_{i}^{*} \leq-\frac{K}{\xi}$ and, following $\mathrm{B} 2,0 \leq D_{i}\left(p_{i}, p_{-i}, q_{-i}\right) \leq K$. 
Define $M=\max \left\{K,-\frac{K}{\xi}\right\}$. Then, for any choice vector $(p, q),\|H(p, q)\| \leq \sqrt{2 n} \cdot M$. Next, we argue that $H$ is continuous. Notice that $f_{i}(p, q):=p_{i}^{*}$ is the unique maximizer of

$$
R_{i}\left(p_{i}\right):=p_{i} \cdot D_{i}\left(p_{i}, p_{-i}, q_{-i}\right)-C_{i}\left(D_{i}\left(p_{i}, p_{-i}, q_{-i}\right)\right)
$$

Because both $D_{i}$ and $C_{i}$ are continuous, the maximum principle implies continuity of $f_{i}$. As the demand of each rival is also continuous, $H$ is continuous. By the Brouwer Fixed Point Theorem, we then know there is a point $\left(p^{*}, q^{*}\right)$ with $H\left(p^{*}, q^{*}\right)=\left(p^{*}, q^{*}\right)$.

Step 3. We show that $\left(p^{*}, q^{*}\right)$ is an equilibrium.

Since $p_{i}^{*}=f_{i}\left(p^{*}, q^{*}\right), p_{i}^{*}$ maximizes the function

$$
R_{i}\left(p_{i}\right):=p_{i} \cdot D_{i}\left(p_{i}, p_{-i}^{*}, q_{-i}^{*}\right)-C_{i}\left(D_{i}\left(p_{i}, p_{-i}^{*}, q_{-i}^{*}\right)\right)
$$

Moreover, $q_{i}^{*}=D_{i}\left(p_{i}^{*}, p_{-i}^{*}, q_{-i}^{*}\right)$. Thus, $\left(p_{i}^{*}, q_{i}^{*}\right)$ is a best reply to $\left(p_{-i}^{*}, q_{-i}^{*}\right)$. As this holds for each firm $i \in N,\left(p^{*}, q^{*}\right)$ is an equilibrium.

This finding somehow generalizes the results of Benassy (1989). Under the assumption of symmetry, he established that (i) for a given number of firms, there does not exist an equilibrium when the degree of substitutability between heterogeneous goods is sufficiently high, and (ii) for a given level of imperfect substitutability, there does exist an equilibrium provided that the number of undertakings is sufficiently large. ${ }^{12}$ Theorem 3 not only allows for asymmetry, but also admits demand curves to be 'very flat' independent of market size. In particular, an equilibrium may also exist when a small number of sellers produce close but imperfect substitutes.

The analysis in this section thus reveals that a broad and natural class of price-quantity games with differentiated products has an equilibrium in pure strategies. This class is 'broad and natural' in the sense that many well-known oligopoly models meet the required assumptions. A few examples are presented in Section 5 of this paper. Moreover, all equilibria exhibit Bertrand behavior. Indeed, even though sellers have no obligation to satisfy the demand forthcoming to them, they are happy to do so.

\section{Price-Quantity Competition with Discontinuous Demand}

Let us now direct our attention to price-quantity competition under the assumption that demand is discontinuous in price. Such a discontinuity property is characteristic of industries

\footnotetext{
${ }^{12}$ The first finding has been confirmed by Canoy (1996), whereas the second conclusion can also be found in Shapley and Shubik (1969).
} 
with undifferentiated products. Though arguably not as realistic as the continuous demand case, this case is of interest because it plays an important role in classical theories of oligopoly and remains popular today.

We start with some preliminaries. As we consider undifferentiated products, customers first buy from the cheapest firm(s). In what follows, we use $P=\min \left\{p_{1}, \ldots, p_{n}\right\}$ to denote the lowest price in the industry and $L=\left\{i \mid p_{i}=P\right\}$ to indicate the collection of sellers charging $P$.

In general, the demand of each firm comprises direct and indirect demand. One implication of the homogeneous goods assumption is that a firm faces direct demand only when there is no cheaper supplier in the market. Let total direct demand be given by $D(P) \geq 0$, which is continuous and strictly decreasing in $P$ as long as $D(P)>0$. It is further assumed that $D(0)>0$. Under the simplifying assumption that the market is split evenly in case of identical prices, direct demand $D_{i}^{d}$ for each firm $i \in N$ is then defined as follows:

$$
D_{i}^{d}(p)= \begin{cases}\frac{1}{|L|} \cdot D(P) & \text { if } i \in L \\ 0 & \text { otherwise }\end{cases}
$$

Each seller may additionally experience indirect or spillover demand. This might occur when one or more firms in $L$ do not satisfy their (direct) demand and these unserved customers still plan to purchase the product or service from another supplier. This indirect demand is denoted by $D_{i}^{s}\left(p, q_{-i}\right)$, for all $i \in N$. Rather than providing a detailed description of the contingent demand structure, we suppose that $D_{i}^{s}\left(p, q_{-i}\right) \leq \alpha \cdot D\left(p_{i}\right)$ with $\alpha \in[0,1]$. That is, spillover demand of firm $i$ at price $p_{i}$ is at most a fraction $\alpha$ of the total demand at that price. Thus, the degree of spillover is captured by the parameter $\alpha$, where $\alpha=1$ and $\alpha=0$ respectively reflect the case of complete spillover and the case where indirect demand is absent. Total demand for the products of firm $i$ is therefore given by

$$
D_{i}\left(p, q_{-i}\right)=D_{i}^{d}(p)+D_{i}^{s}\left(p, q_{-i}\right), \forall i \in N
$$

Let us now first consider the case where unserved customers may visit higher-priced firms. In line with most of the existing literature, we begin by showing conditions under which an equilibrium does not exist. Then, we will provide sufficient conditions under which an equilibrium does exist. Specifically, we will show that there are rationing equilibria when spillover demand is not too strong.

We make the following assumptions on cost and demand. In stating these assumptions, define $Z_{i}\left(p_{-i}, q_{-i}\right)\left(p_{i}\right)=D_{i}\left(p_{i}, p_{-i}, q_{-i}\right)$ as the residual demand of firm $i$. 
For all $i \in N$ :

C1 If $q_{i} \geq D_{i}\left(p, q_{-i}\right)$, and $p_{i}^{\prime}<p_{i}$, then for every $j \neq i$ with $p_{j} \geq p_{i}, D_{i}\left(p_{i}^{\prime}, p_{-i}, q_{-i}\right) \geq$ $D_{i}\left(p, q_{-i}\right)+D_{j}\left(p, q_{-j}\right)$. If $q_{i} \leq D_{i}\left(p, q_{-i}\right)$, then for every $j \neq i$ with $p_{j}>p_{i}, D_{i}\left(p, q_{-i}\right)-$ $q_{i} \geq D_{j}\left(p, q_{-j}\right)$.

C2 $Z_{i}\left(p_{-i}, q_{-i}\right)\left(p_{i}^{\prime}\right) \leq Z_{i}\left(p_{-i}, q_{-i}\right)\left(p_{i}\right)$ for all $p_{i}^{\prime}>p_{i}$.

C3 For all $(p, q), Z_{i}\left(p_{-i}, q_{-i}\right)(0)>0$. We also assume that for all $(p, q)$ with $p>0$ there is $p_{i}^{\prime}>0$ with $Z_{i}\left(p_{-i}, q_{-i}\right)\left(p_{i}^{\prime}\right)>0$.

C4 Let $(p, q)$ be such that $q_{j} \leq D_{j}\left(p, q_{-j}\right)$ for all $j$. Then there is an $\varepsilon>0$ and $K>0$ such that for every $i$ and $p_{i}^{\prime}$ with $p_{i}<p_{i}^{\prime}<p_{i}+\varepsilon$ it holds that

$$
Z_{i}\left(p_{-i}, q_{-i}\right)\left(p_{i}^{\prime}\right) \geq Z_{i}\left(p_{-i}, q_{-i}\right)\left(p_{i}\right)-K \cdot\left(p_{i}^{\prime}-p_{i}\right)
$$

As an easy consequence, also using that $Z_{i}\left(p_{-i}, q_{-i}\right)$ is not increasing, at such a point $(p, q)$ the function $Z_{i}\left(p_{-i}, q_{-i}\right)$ is right-continuous at $p_{i}$.

C5 $C_{i}\left(q_{i}\right)$ is continuously differentiable with $C_{i}^{\prime}(0)=0$ and $C_{i}^{\prime}\left(q_{i}\right)$ is strictly increasing at all $q_{i}>0$.

C2-C3 and C5 are fairly standard. Assumption C1 captures the homogeneity of the product. The logic of the first part concerns direct demand at firm $j$. Consumers initially go to the firm with the lowest price and may only visit higher-priced firms when the lowest-price firms produce strictly below their demand. The logic of the second part concerns indirect demand at firm $j$. Indirect demand at firm $j$ cannot exceed excess demand at firm $i$. Finally, C4 states that, when all firms produce at most their demand, then a firm cannot lose too much of its demand when it increases its price slightly. The logic is that, once consumers cannot buy at other suppliers, most of them would accept a limited price increase. Violation of this principle could only be established by a sudden drastic drop in total demand.

Theorem 4. Under C1-C5, there exists no equilibrium.

Proof Suppose that $p^{*}=\left(p_{1}^{*}, \ldots, p_{n}^{*}\right)$ and $q^{*}=\left(q_{1}^{*}, \ldots, q_{n}^{*}\right)$ is an equilibrium. We proceed in six steps to derive a contradiction.

Step 1. For all $i \in N, q_{i}^{*}=D_{i}\left(p^{*}, q_{-i}^{*}\right)$.

By Lemma $1, q_{j}^{*} \leq D_{j}\left(p^{*}, q_{-j}^{*}\right)$ for all $j$. Suppose that $q_{i}^{*}<D_{i}\left(p^{*}, q_{-i}^{*}\right)$. Since $q_{j}^{*} \leq D_{j}\left(p^{*}, q_{-j}^{*}\right)$ for all $j$, by assumptions $\mathrm{C} 2$ and $\mathrm{C} 4, Z_{i}\left(p_{-i}^{*}, q_{-i}^{*}\right)$ is right-continuous at $p_{i}^{*}$. So, firm $i$ can 
improve its payoff by raising the price slightly, keeping production at the same level, and still selling the same amount $q_{i}^{*}$ as at $p_{i}^{*}$.

Step 2. For all $i \in N, \Pi_{i}\left(p^{*}, q^{*}\right)>0$.

Consider firm $i$ and $\left(p_{-i}^{*}, q_{-i}^{*}\right)$. It suffices to show that there is a price-quantity pair $\left(p_{i}, q_{i}\right)$ for which firm $i$ 's profits are strictly positive.

Suppose $p_{i}^{*}=0$. Then profits for firm $i$ are at most zero. By Step 1 and C4 we know that $Z_{i}\left(p_{-i}^{*}, q_{-i}^{*}\right)\left(p_{i}\right)$ is right-continuous at $p_{i}^{*}=0$. Since $Z_{i}\left(p_{-i}^{*}, q_{-i}^{*}\right)(0)>0$ by C3, there is $p_{i}>0$ with $Z_{i}\left(p_{-i}^{*}, q_{-i}^{*}\right)\left(p_{i}\right)>0$. So, by C5, for sufficiently small $q_{i}$, profits for firm $i$ are strictly positive. Contradiction.

So, $p_{j}^{*}>0$ for all $j$. Then, for firm $i$, by C3 there is $p_{i}>0$ with $Z_{i}\left(p_{-i}^{*}, q_{-i}^{*}\right)\left(p_{i}\right)>0$. So, again by $\mathrm{C} 5$, for sufficiently small $q_{i}$, profits for firm $i$ are strictly positive.

Step 3. For each two firms $i, j \in N, p_{i}^{*}=p_{j}^{*}=P^{*}$.

Consider two firms, $i$ and $j$, and suppose that $p_{j}^{*}>p_{i}^{*}$. By Step 1, we know that $q_{i}^{*}=$ $D_{i}\left(p^{*}, q_{-i}^{*}\right)$. It then follows from C1 that $D_{j}\left(p^{*}, q_{-j}^{*}\right)=0$, which implies that firm $j$ 's profits are at most zero. This contradicts Step 2. We conclude that $p_{i}^{*}=P^{*}, \forall i \in N$.

Step 4. For all $i \in N, P^{*} \geq C_{i}^{\prime}\left(q_{i}^{*}\right)$.

Consider firm $i$. Given price $P^{*}, q_{i}^{*}$ solves

$$
\begin{aligned}
& \max _{q_{i}} P^{*} \cdot q_{i}-C_{i}\left(q_{i}\right) \\
& \quad \text { s.t. } \\
& 0 \leq q_{i} \leq D_{i}\left(p^{*}, q_{-i}^{*}\right) .
\end{aligned}
$$

As the objective function is strictly concave in $q_{i}$, we either have that $q_{i}^{*}<D_{i}\left(p^{*}, q_{-i}^{*}\right)$ and $P^{*}=C_{i}^{\prime}\left(q_{i}^{*}\right)$ or $q_{i}^{*}=D_{i}\left(p^{*}, q_{-i}^{*}\right)$ and $P^{*} \geq C_{i}^{\prime}\left(q_{i}^{*}\right)$. By Step 1 , we know that $q_{i}^{*}=D_{i}\left(p^{*}, q_{-i}^{*}\right)$ and therefore $P^{*} \geq C_{i}^{\prime}\left(q_{i}^{*}\right), \forall i \in N$.

Step 5. For all $i \in N, P^{*} \neq C_{i}^{\prime}\left(q_{i}^{*}\right)$.

Consider firm $i$ and suppose that $P^{*}=C_{i}^{\prime}\left(q_{i}^{*}\right)$. Following Step 1, we can choose $\varepsilon>0$ and $K>0$ such that C4 holds. Take $L>K$ and consider the following optimization problem:

$$
\begin{aligned}
& \max p_{i} \cdot q_{i}-C_{i}\left(q_{i}\right) \\
& \quad \text { s.t. } \\
& q_{i}=Z_{i}\left(p_{-i}^{*}, q_{-i}^{*}\right)\left(P^{*}\right)-L \cdot\left(p_{i}-P^{*}\right) \\
& \quad \text { and } \\
& p_{i} \geq P^{*} .
\end{aligned}
$$

Using Lagrange optimization, we find that for an optimal price-quantity pair $\left(p_{i}, q_{i}\right)$ it holds 
that

$$
p_{i}=C_{i}^{\prime}\left(q_{i}\right)+\frac{q_{i}}{L} .
$$

Clearly, if $q_{i}>q_{i}^{*}$, then $p_{i}>p_{i}^{*}$. Moreover, by choosing a $q_{i}>q_{i}^{*}$ sufficiently close to $q_{i}^{*}$ as well as a sufficiently large $L$, we can ensure that

$$
p_{i}=C_{i}^{\prime}\left(q_{i}\right)+\frac{q_{i}}{L}<C_{i}^{\prime}\left(q_{i}^{*}\right)+\frac{\varepsilon}{2}+\frac{q_{i}}{L}<p_{i}^{*}+\varepsilon .
$$

Thus, at $\left(p_{i}, q_{i}\right)$ profits are strictly higher than at $\left(P^{*}, q_{i}^{*}\right)$ provided that firm $i$ sells the entire quantity of output $q_{i}$.

Finally, following our choice of $\varepsilon$ and $K$,

$$
Z_{i}\left(p_{-i}^{*}, q_{-i}^{*}\right)\left(p_{i}\right) \geq Z_{i}\left(p_{-i}^{*}, q_{-i}^{*}\right)\left(P^{*}\right)-K \cdot\left(p_{i}-P^{*}\right)>Z_{i}\left(p_{-i}^{*}, q_{-i}^{*}\right)\left(P^{*}\right)-L \cdot\left(p_{i}-P^{*}\right)=q_{i} .
$$

Hence, firm $i$ will indeed sell $q_{i}$. We conclude that $P^{*} \neq C_{i}^{\prime}\left(q_{i}^{*}\right), \forall i \in N$.

Step 6. For all $i \in N, P^{*} \leq C_{i}^{\prime}\left(q_{i}^{*}\right)$.

Consider firm $i$ and suppose that $P^{*}>C_{i}^{\prime}\left(q_{i}^{*}\right)$. We construct $p_{i}^{\prime}$ and $q_{i}^{\prime}$ such that $\Pi_{i}\left(p^{\prime}, q^{\prime}\right)>$ $\Pi_{i}\left(p^{*}, q^{*}\right)$, where $p^{\prime}=\left(p_{i}^{\prime}, p_{-i}^{*}\right)$ and $q^{\prime}=\left(q_{i}^{\prime}, q_{-i}^{*}\right)$.

We first define $q_{i}^{\prime}$. Consider a price $p_{i}<p_{i}^{*}$. Following Step 1 and 3 , we can apply C2 so that for every $j \neq i$,

$$
D_{i}\left(p_{i}, p_{-i}^{*}, q_{-i}^{*}\right) \geq D_{i}\left(p^{*}, q_{-i}^{*}\right)+D_{j}\left(p^{*}, q_{-j}^{*}\right) .
$$

Take any firm $j \neq i$. By Step 2, we know that $D_{j}\left(p^{*}, q_{-j}^{*}\right)>0$. Now define $A=D_{j}\left(p^{*}, q_{-j}^{*}\right)$. By C5, $C_{i}\left(q_{i}\right)$ is continuous. Thus, we can take $q_{i}^{\prime}>q_{i}^{*}$ such that $C_{i}^{\prime}\left(q_{i}^{\prime}\right)<P^{*}$ and $q_{i}^{\prime}<$ $D_{i}\left(p^{*}, q_{-i}^{*}\right)+A$.

Next, we define $p_{i}^{\prime}$. Given $p_{i}^{*}$, define the function

$$
F_{i}\left(q_{i}\right)=p_{i}^{*} \cdot q_{i}-C_{i}\left(q_{i}\right)
$$

By C5, $F_{i}$ is strictly concave, $F_{i} \geq 0$ and $F_{i}(0)=0$. So, $F_{i}$ is increasing as long as $P^{*}>\frac{d C_{i}}{d q_{i}}\left(q_{i}\right)$. Since $q_{i}^{\prime}>q_{i}^{*}$, and still $\frac{d C_{i}}{d q_{i}}\left(q_{i}^{\prime}\right)<P^{*}$, it follows that

$$
F_{i}\left(q_{i}^{\prime}\right)>F_{i}\left(p_{i}^{*}\right)
$$

Now notice that the expression

$$
p_{i} \cdot q_{i}^{\prime}-C_{i}\left(q_{i}^{\prime}\right)
$$

converges to $p_{i}^{*} \cdot q_{i}^{\prime}-C_{i}\left(q_{i}^{\prime}\right)=F_{i}\left(q_{i}^{\prime}\right)$ as $p_{i}$ converges to $p_{i}^{*}$. So, we can choose $p_{i}^{\prime}<p_{i}^{*}$ with

$$
p_{i}^{\prime} \cdot q_{i}^{\prime}-C_{i}\left(q_{i}^{\prime}\right)>F_{i}\left(p^{*}\right)
$$


Now let firm $i$ charge price $p_{i}^{\prime}$ and produce quantity $q_{i}^{\prime}$. Write $p^{\prime}=\left(p_{-i}^{*}, p_{i}^{\prime}\right)$. We show that $\Pi_{i}\left(p^{\prime}, q^{\prime}\right)>\Pi_{i}\left(p^{*}, q^{*}\right)$.

Notice that

$$
D_{i}\left(p^{\prime}, q_{-i}^{\prime}\right)=D_{i}\left(p_{-i}^{*}, q_{-i}^{*}, p_{i}^{\prime}\right) \geq D_{i}\left(p^{*}, q_{-i}^{*}\right)+A>q_{i}^{\prime} .
$$

So, $q_{i}^{\prime}<D_{i}\left(p^{\prime}, q_{-i}^{\prime}\right)$. It follows that

$$
\Pi_{i}\left(p^{\prime}, q^{\prime}\right)=p_{i}^{\prime} \cdot q_{i}^{\prime}-C_{i}\left(q_{i}^{\prime}\right)>F_{i}\left(p^{*}\right)=\Pi_{i}\left(p^{*}, q^{*}\right) .
$$

Hence, $\Pi_{i}\left(p^{\prime}, q^{\prime}\right)>\Pi_{i}\left(p^{*}, q^{*}\right)$.

Finally, combining Step 4, 5 and 6 yields a contradiction.

We now somewhat strengthen our assumptions on costs. In the following, it is assumed that $C_{i}\left(q_{i}\right) \geq 0$ is twice continuously differentiable and strictly convex. More precisely, for each $i \in N$, we assume $\frac{d^{2} C_{i}}{d q_{i}^{2}} \geq \xi$ for some $\xi>0$.

Theorem 5. $\exists \bar{\alpha} \in(0,1)$ such that for all $\alpha<\bar{\alpha}$ rationing equilibria exist.

Proof Consider a value $P>0$ and firm $i$. Since we assume that $\frac{d^{2} C_{i}}{d q_{i}^{2}} \geq \xi$ for some $\xi>0$, we can compute $q_{i}(P)>0$ such that $\frac{d C_{i}}{d q_{i}}\left(q_{i}(P)\right)=P$.

Since $D$ and all functions $\frac{d C_{i}}{d q_{i}}$ are continuous, and $D(0)>0$, we can find $P^{*}$ with $q_{i}\left(P^{*}\right)<$ $\frac{D\left(P^{*}\right)}{n}$ for all $i$. Write $q_{i}^{*}=q_{i}\left(P^{*}\right)$. We argue that

$$
\left(p^{*}, q^{*}\right)=\left(P^{*}, \ldots, P^{*}, q_{1}^{*}, \ldots, q_{n}^{*}\right)
$$

is an equilibrium. Consider firm $i$ and let the strategies of the other firms be as stated above. We argue that $\left(P^{*}, q_{i}^{*}\right)$ is a best response.

We argue that $\left(P^{*}, q_{i}^{*}\right)$ is a best response among all responses $\left(p_{i}, q_{i}\right)$ with $p_{i} \leq P^{*}$. Suppose $p_{i} \leq P^{*}$. Also suppose that $q_{i}$ is a best choice given $p_{i}$. We first argue that $p_{i}=\frac{d C_{i}}{d q_{i}}\left(q_{i}\right)$.

The equation $p_{i}=\frac{d C_{i}}{d q_{i}}\left(q_{i}\right)$ has a solution, say $q_{i}^{\prime}$. Notice that $p_{i}=\frac{d C_{i}}{d q_{i}}\left(q_{i}^{\prime}\right), P^{*} \leq \frac{d C_{i}}{d q_{i}}\left(q_{i}^{*}\right)$, and $p_{i} \leq P^{*}$. So, $\frac{d C_{i}}{d q_{i}}\left(q_{i}^{\prime}\right) \leq \frac{d C_{i}}{d q_{i}}\left(q_{i}^{*}\right)$. Thus, since $\frac{d C_{i}}{d q_{i}}$ is strictly increasing, $q_{i}^{\prime} \leq q_{i}^{*}$. However, $q_{i}^{*}=q_{i}\left(P^{*}\right)<\frac{D\left(P^{*}\right)}{n}$ by construction. Thus, since $D$ is strictly decreasing, also $q_{i}^{\prime}<\frac{D\left(P^{*}\right)}{n}$.

So, since the profit function $\Pi_{i}=p_{i} \cdot q_{i}-C_{i}\left(q_{i}\right)$ is concave in $q_{i}$, the best choice for $q_{i}$ given $p_{i}$ satisfies $p_{i}=\frac{d C_{i}}{d q_{i}}\left(q_{i}\right)$.

Thus, in any best response $p_{i}$ with $p_{i} \leq P^{*}$, it holds that $p_{i}=\frac{d C_{i}}{d q_{i}}\left(q_{i}\right)$. So, effectively firm $i$ maximizes the function

$$
\Pi_{i}=\frac{d C_{i}}{d q_{i}}\left(q_{i}\right) \cdot q_{i}-C_{i}\left(q_{i}\right)
$$


with a first derivative of

$$
\frac{d C_{i}}{d q_{i}}+q_{i} \cdot \frac{d^{2} C_{i}}{d q_{i}^{2}}-\frac{d C_{i}}{d q_{i}}=q_{i} \cdot \frac{d^{2} C_{i}}{d q_{i}^{2}} .
$$

This last expression is strictly positive. So, the profit function is strictly increasing in $q_{i}$. Thus, the optimal choice among all choices $p_{i} \leq P^{*}$ is at $p_{i}=P^{*}$, with a corresponding optimal quantity choice of $q_{i}^{*}$.

Suppose $p_{i}>P$. Let $P_{0}$ be such that $D\left(P_{0}\right)=0$. We may assume that $p_{i} \leq P_{0}$. Write

$$
\Pi_{i}^{*}=P^{*} \cdot \frac{D\left(P^{*}\right)}{n}-C_{i}\left(q_{i}^{*}\right)
$$

the profit for firm $i$ when $\left(p^{*}, q^{*}\right)$ is played. Also write $\Pi_{i}$ for the profit when firm $i$ plays $\left(p_{i}, q_{i}\right)$ instead. Suppose that $\alpha<\frac{\Pi_{i}^{*}}{P_{0} \cdot D\left(P^{*}\right)}$. We argue that $\Pi_{i}<\Pi_{i}^{*}$.

When $p_{i}>P^{*}$, firm $i$ has direct demand zero. So, $D_{i}(p, q)=D_{i}^{s}\left(p, q_{-i}\right) \leq \alpha \cdot D\left(p_{i}\right)$. So, for the resulting profit

$\Pi_{i}=p_{i} \cdot D_{i}\left(p, q_{-i}\right)-C_{i}\left(q_{i}\right) \leq p_{i} \cdot D_{i}\left(p, q_{-i}\right) \leq P_{0} \cdot D_{i}\left(p, q_{-i}\right) \leq P_{0} \cdot \alpha \cdot D\left(p_{i}\right) \leq P_{0} \cdot \alpha \cdot D\left(P^{*}\right)$.

So, since $\alpha<\frac{\Pi_{i}^{*}}{P_{0} \cdot D\left(P^{*}\right)}$, we find that $\Pi_{i} \leq \Pi_{i}^{*}$.

Finally, note that, for any choice of $P^{*}$ as above, the corresponding quantity $q_{i}^{*}$ in the equilibrium is strictly less than the demand $\frac{D\left(P^{*}\right)}{n}$ for firm $i$. Hence, we find that rationing equilibria exist in this model.

Thus, there exist pure-strategy solutions provided that spillover demand is not too strong. The logic behind this result is that none of the firms should have an incentive to elevate prices. This is the case when a price increase would result in a sufficient drop of sales. In the context of our model, this implies that $\alpha$ must be sufficiently small. The idea that a significant fall in demand is required for the existence of equilibrium is at the heart of various known solutions to the Edgeworth paradox. ${ }^{13}$

What is perhaps more surprising concerns the type of equilibrium. Indeed, there is an interesting contrast with the pioneering work of Shubik $(1955,1960)$. Even though he did not solve the Edgeworth paradox, he did establish the efficient point as the sole equilibrium candidate. ${ }^{14}$ In the efficient point, firms price at marginal cost and saturate the market. The above result confirms the first requirement, i.e., firms indeed produce at a level where price

\footnotetext{
${ }^{13}$ See, among others, Levitan and Shubik (1972) and Dixon (1990, 1992). The underlying logic can already be found in Shubik $(1955,1960)$. More recently, Tasnádi (1999) proves the existence of a pure-strategy equilibrium when demand is sufficiently elastic.

${ }^{14}$ See Theorem 2 in Shubik (1960, p. 100).
} 
equals marginal cost. Yet, it does not confirm that firms meet the forthcoming demand at the price set. In fact, sellers satisfy only part of their customers in equilibrium. These shortages imply that prices are too low to be efficient. The reason for firms not to increase their prices is that this would lead to a significant drop in sales.

This is of course not to say that the efficient point is never an equilibrium. In fact, under the assumption of identical technologies and zero spillover demand, there does exist a Bertrand equilibrium with price equal to marginal cost. In accordance with Theorem 5 , however, there also still is a range of rationing equilibria.

Theorem 6. Assume $\alpha=0$ and $C_{i}\left(q_{i}\right)=C\left(q_{i}\right), \forall i \in N$. There exists a set of symmetric equilibria. Precisely one of these equilibria is a Bertrand equilibrium. The remaining equilibria are rationing equilibria.

Proof In this symmetric model, the equilibria

$$
\left(p^{*}, q^{*}\right)=\left(P^{*}, \ldots, P^{*}, q_{1}^{*}, \ldots, q_{n}^{*}\right)
$$

from Theorem 5 reduce to

$$
\left(P^{*}, \ldots, P^{*}, q^{*}, \ldots, q^{*}\right)
$$

In this form, $q * \leq \frac{D\left(P^{*}\right)}{n}$. All equilibria with $q^{*}<\frac{D\left(P^{*}\right)}{n}$ are rationing equilibria. The equilibrium with $q^{*}=\frac{D\left(P^{*}\right)}{n}$ is a Bertrand equilibrium.

In contrast to the continuous demand case, Theorems 5 and 6 show that when demand is discontinuous the degree of spillover demand plays a critical role in establishing existence. When spillover demand is not too strong, firms have no incentive to put their focus on indirect rather than direct demand. What could be reasons for such limited spillover? One obvious possibility is that a substantial part of the unlucky customers may prefer to leave the market after they have failed to obtain the product or service directly. We further suspect that spillover demand will not endure in fairly stable markets. If we make the reasonable assumption that time is valuable and transportation costly, then it is evidently suboptimal for customers to repeatedly receive their product indirectly. Indirect demand is therefore likely to diminish in cases where the same customers are served each period. ${ }^{15}$

The above results were derived under the assumption of decreasing returns to scale. Our findings would be different with constant returns, although the underlying logic remains.

\footnotetext{
${ }^{15}$ This suggests that spillover demand is more likely to last when products are sold on a first-come-first-served basis rather than under efficient rationing or any other situation where the same customers get the product.
} 
One notable difference with the case of decreasing returns is that, under the assumption that firms choose to meet their demand when this yields zero economic profits, rationing equilibria will not exist. This would leave Bertrand equilibria as the only potential solution. Results, in this case, have more of an 'all-or-nothing' flavor. With hetereogeneous costs, it will be the lowest-cost firm that serves the entire market. With identical cost functions, by contrast, an equilibrium exists when there is no spillover demand (i.e., when $\alpha=0$ ). Note that this latter outcome is equivalent to the traditional Bertrand-Nash equilibrium.

\section{$5 \quad$ Examples}

Let us now illustrate our main findings with a few representative examples. In this section, we present five cases; the first three of which deal with a differentiated duopoly. Example 1 serves to show how equilibrium prices and quantities can be derived in a well-known textbook model. Example 2 illustrates how an equilibrium may fail to exist when demand is nondifferentiable (a violation of B1), whereas Example 3 shows that an equilibrium may still exist when demand functions exhibit a kink. Specifically, Example 2 and 3 highlight how (non-)existence of equilibrium depends critically on whether a firm's spillover demand is a function of its own selling price. The final two examples, Example 4 and 5, consider a homogeneous good oligopoly with and without spillover demand.

\subsection{Heterogeneous Products}

EXAMPLE 1. (Bowley (1924)) In this first example, we examine a well-known representative consumer model as introduced by Bowley (1924). The (quasi-linear) utility of consuming a quantity $s_{1}$ at a price $p_{1}$ and a quantity $s_{2}$ at price $p_{2}$ is given by

$$
U=\alpha \cdot\left(s_{1}+s_{2}\right)-\frac{1}{2} \cdot \beta \cdot\left(s_{1}^{2}+2 \theta s_{1} s_{2}+s_{2}^{2}\right)-p_{1} \cdot s_{1}-p_{2} \cdot s_{2},
$$

which is the gain from consumption

$$
V=\alpha \cdot\left(s_{1}+s_{2}\right)-\frac{1}{2} \cdot \beta \cdot\left(s_{1}^{2}+2 \theta s_{1} s_{2}+s_{2}^{2}\right)
$$

minus the total expenditure of $p_{1} \cdot s_{1}+p_{2} \cdot s_{2}$. The degree of differentiation is captured by the differentiation (or 'distance') parameter $\theta \in[0,1]$. When $\theta=1$, goods are perfect substitutes, whereas both goods are independent in demand when $\theta=0$. Notice that utility depends on sales $\left(s_{i}\right)$ and not on demand $\left(D_{i}\right)$ or production $\left(q_{i}\right)$. For simplicity, it is assumed in the following that firms have common, constant marginal cost $c>0$. 
To determine the utility-maximizing allocation of sales, take the first-order conditions with respect to $s_{1}$ and $s_{2}$ :

$$
\begin{aligned}
& \alpha-\beta s_{1}-\beta \theta s_{2}-p_{1}=0, \\
& \alpha-\beta s_{2}-\beta \theta s_{1}-p_{2}=0 .
\end{aligned}
$$

Rearranging gives the inverse demand function for both firms:

$$
\begin{aligned}
& p_{1}=\alpha-\beta \cdot\left(s_{1}+\theta s_{2}\right), \\
& p_{2}=\alpha-\beta \cdot\left(s_{2}+\theta s_{1}\right) .
\end{aligned}
$$

Thus, given prices $p_{1}$ and $p_{2}$, the representative consumer aims to acquire

$$
\begin{aligned}
& s_{1}=\frac{1}{\beta \cdot(1+\theta)} \cdot\left[\alpha-\frac{p_{1}}{1-\theta}+\frac{\theta p_{2}}{1-\theta}\right], \\
& s_{2}=\frac{1}{\beta \cdot(1+\theta)} \cdot\left[\alpha-\frac{p_{2}}{1-\theta}+\frac{\theta p_{1}}{1-\theta}\right] .
\end{aligned}
$$

Note that this model meets the requirements of A2 and B1-B3 provided that production is not too expensive. It then follows from Theorem 3 that there is an equilibrium. Moreover, by Lemma 2 we know that this equilibrium is a Bertrand equilibrium. Thus, Firm 1 maximizes

$$
\Pi_{1}=\left(p_{1}-c\right) \cdot \frac{1}{\beta \cdot(1+\theta)} \cdot\left[\alpha-\frac{p_{1}}{1-\theta}+\frac{\theta p_{2}}{1-\theta}\right],
$$

which yields the following corresponding best reply function:

$$
p_{1}=\frac{1}{2} \cdot\left[c+(1-\theta) \cdot \alpha+\theta \cdot p_{2}\right] .
$$

Using symmetry and solving the resulting system of best response functions gives

$$
p_{1}^{*}=p_{2}^{*}=\frac{c+\alpha \cdot(1-\theta)}{2-\theta} \text { and } D_{1}=D_{2}=q_{1}^{*}=q_{2}^{*}=\frac{\alpha-c}{\beta \cdot(1+\theta) \cdot(2-\theta)} .
$$

Suppose, for instance, that $\alpha=18, \beta=\frac{2}{3}, \theta=\frac{1}{2}$ and $C_{i}\left(q_{i}\right)=3 q_{i}$ for $i=1,2$. This gives demand functions $D_{1}\left(p_{1}, p_{2}\right)=\left[18-2 p_{1}+p_{2}\right]_{+}$and $D_{2}\left(p_{1}, p_{2}\right)=\left[18-2 p_{2}+p_{1}\right]_{+}$and the following equilibrium prices and quantities:

$$
p_{1}^{*}=p_{2}^{*}=\frac{c+\alpha \cdot(1-\theta)}{2-\theta}=8 \text { and } D_{1}=D_{2}=q_{1}^{*}=q_{2}^{*}=\frac{\alpha-c}{\beta \cdot(1+\theta) \cdot(2-\theta)}=10 .
$$

EXAMPLE 2. ((Almost) Friedman (1988)) Let us now use the previous specifications (i.e., $\alpha=18, \beta=\frac{2}{3}, \theta=\frac{1}{2}$ and $c=3$ ) and extend the model by adding the possibility of complete 
spillover. Thus, firm demand comprises all competitors' unserved customers. Demand for the products of Firm 1 is then given by

$$
D_{1}\left(p_{1}, p_{2}, q_{2}\right)= \begin{cases}{\left[18-2 p_{1}+p_{2}\right]_{+}} & \text {if } 18+p_{1}-2 p_{2} \leq q_{2}, \\ {\left[36-p_{1}-p_{2}-q_{2}\right]_{+}} & \text {if } 18+p_{1}-2 p_{2}>q_{2} .\end{cases}
$$

The demand function for Firm 2 is symmetric. Such a setting closely mimics the framework of Friedman (1988) and the underlying logic for non-existence of equilibrium is comparable. ${ }^{16}$

To see that this demand specification does indeed not admit an equilibrium, first observe that A1 and A2 still hold. Hence, Lemma 2 applies so that in equilibrium $q_{i}=D_{i}$, for $i=1,2$. This implies $D_{1}=\left[18-2 p_{1}+p_{2}\right]_{+}$and $D_{2}=\left[18-2 p_{2}+p_{1}\right]_{+}$. Note that this is precisely the demand structure of Example 1 leaving $p_{1}=p_{2}=8$ and $q_{1}=q_{2}=10$ as the only equilibrium candidate. Given that $p_{2}=8$ and $q_{2}=10$, the demand function of Firm 1 reduces to

$$
D_{1}\left(p_{1}\right)= \begin{cases}{\left[26-2 p_{1}\right]_{+}} & \text {if } 2+p_{1} \leq 10 \\ {\left[18-p_{1}\right]_{+}} & \text {if } 2+p_{1}>10\end{cases}
$$

It can now be easily verified that $\left(p_{1}, q_{1}\right)=(8,10)$ is no longer a best reply. In fact, given $\left(p_{2}, q_{2}\right)=(8,10)$, Firm 1 has an incentive to 'generate spillover demand' by hiking its price. Specifically, it maximizes

$$
\Pi_{1}=\left(p_{1}-3\right) \cdot\left[18-p_{1}\right]_{+},
$$

which reaches its maximum at $p_{1}=\frac{21}{2}$. Thus, in this case, a best reply to $\left(p_{2}, q_{2}\right)=(8,10)$ is no longer $\left(p_{1}, q_{1}\right)=(8,10)$, but $\left(p_{1}, q_{1}\right)=(10.5,7.5)$.

EXAmple 3. (Kinked Demand with a Solution) Following Friedman (1988) and the previous example, it is tempting to conclude that no equilibrium can exist in models with complete spillover. We will now present an example showing that such a conclusion would be premature. We again use the above Bowley model and assume that $c=3, \beta=1$ and $\theta=0$ (i.e., both firms are (local) monopolists). Absent spillover, demand functions are

$$
\begin{aligned}
& D_{1}\left(p_{1}\right)=\alpha-p_{1}, \\
& D_{2}\left(p_{2}\right)=\alpha-p_{2} .
\end{aligned}
$$

In this case, equilibrium prices and quantities are respectively given by $p_{1}^{*}=p_{2}^{*}=\frac{\alpha+3}{2}$ and $q_{1}^{*}=q_{2}^{*}=\frac{\alpha-3}{2}$.

\footnotetext{
${ }^{16}$ Formally, this setting does not fall within the class of models considered by Friedman (1988) as it allows for strictly positive demand even when direct demand is zero. That is, for a sufficiently high price, demand of a firm may consist exclusively of customers that visited the rival first. Unfortunately, we have been unable so far to construct meaningful or tractable demand specifications that fully fit the Friedman (1988) context.
} 
In contrast, the demand functions with complete spillover are

$$
\begin{aligned}
& D_{1}\left(p_{1}, p_{2}, q_{2}\right)=\left[\alpha-p_{1}\right]_{+}+\left[\alpha-p_{2}-q_{2}\right]_{+}, \\
& D_{2}\left(p_{2}, p_{1}, q_{1}\right)=\left[\alpha-p_{2}\right]_{+}+\left[\alpha-p_{1}-q_{1}\right]_{+} .
\end{aligned}
$$

By Lemma 2, we know that in equilibrium $q_{i}=D_{i}$, for $i=1,2$. Thus, actual spillover is zero and therefore $q_{1}^{*}=\alpha-p_{1}^{*}$ and $q_{2}^{*}=\alpha-p_{2}^{*}$. We conclude that there is an equilibrium with $p_{1}^{*}=p_{2}^{*}=\frac{\alpha+3}{2}$ and $q_{1}^{*}=q_{2}^{*}=\frac{\alpha-3}{2}$, which is identical to the equilibrium absent spillover demand. ${ }^{17}$

It is worth highlighting the difference with the previous example as in both cases the demand function exhibits a kink. The fundamental distinction lies in 'the nature of the kink'. In this example, it is due to the production level of the rival. In particular, the indirect demand is independent of the own selling price. In Example 2, by contrast, the indirect demand does depend on the own price. In other words, the demand functions exhibit a kink in $p_{i}$ and it is precisely this property that in Example 2 destroys the equilibrium. ${ }^{18}$

\subsection{Homogeneous Products}

EXAmple 4. (No Spillover) Let total demand be given by $D(P)=A-P$, with $A>0$. Moreover, let $C_{i}\left(q_{i}\right)=q_{i}^{2}$, for all $i \in N$. This is a symmetric model and a special case of the model in Section 4 with $\alpha=0$. Let $P^{*}$ be a price associated with a symmetric equilibrium. As $C_{i}^{\prime}\left(q_{i}\right)=2 \cdot q_{i}$, it must be true that $q_{i}^{*}=\frac{1}{2} \cdot P^{*}$.

In equilibrium, it holds that $q_{i}^{*} \leq \frac{D\left(P^{*}\right)}{n}$ or $\frac{1}{2} \cdot P^{*} \leq \frac{A-P^{*}}{n}$, which can be rearranged to $P^{*} \leq \frac{2 A}{n+2}$. If $P^{*}<\frac{2 A}{n+2}$, then the equilibrium is a rationing equilibrium. The equilibrium is a Bertrand equilibrium when $P^{*}=\frac{2 A}{n+2}$.

EXAMPle 5. (Spillover) Consider the model of the previous example, but now with spillover demand (i.e., $\alpha>0$ ). Let $P_{1}:=P$ and define recursively $P_{k+1}=\min \left\{p_{i} \mid p_{i}>P_{k}\right\}$. For each $k$, write $N_{k}=\left\{i \mid p_{i}=P_{k}\right\}$ and let $Q_{k}=\sum_{i \in N_{k}} q_{i}$.

Demand is defined as follows. Let $A_{1}=A$ and $D^{d}(P)=A_{1}-P$. Suppose that $D^{k}$ is defined recursively and let $A_{k+1}=D^{k}\left(P_{k}\right)-Q_{k}$. Furthermore, $D^{k+1}(P)=\alpha \cdot A_{k+1}-\left(P-P_{k}\right)$ for $P_{k}<P \leq P_{k+1}$. For all $i \in N_{k}$, demand is then given by $\frac{D^{k}\left(p_{i}\right)}{\left|N_{k}\right|}$.

Consider the Bertrand equilibrium of Example 4 with $P^{*}=\frac{2 A}{n+2}$ and $q_{i}^{*}=\frac{A}{n+2}$, for all $i \in N$. This equilibrium was derived for $\alpha=0$. We now determine for which values of $\alpha$ this

\footnotetext{
${ }^{17}$ A similar result can be derived in the spatial model of Hotelling (1929). See Alger (1979, Theorem 3.1).

${ }^{18} \mathrm{It}$ is furthermore noteworthy that assumption B1 may also be satisfied when customers take into account other factors than price. For instance, when there are costs associated with queuing, buyers might approach another supplier well before their most preferred choice (absent queuing costs) is sold out.
} 
equilibrium remains an equilibrium.

As before, cutting price will not lead to an increase in profits. For $p_{i}>P^{*}$, demand is given by $D^{s}\left(p_{i}\right)=\alpha \cdot A_{2}-\left(p_{i}-P^{*}\right)$, where

$$
A_{2}=D^{d}\left(P_{1}\right)-Q_{1}=D\left(P^{*}\right)-\frac{(n-1) \cdot A}{n+2}=A-\frac{2 A}{n+2}-\frac{(n-1) \cdot A}{n+2}=\frac{A}{n+2} .
$$

Substituting in the demand function gives

$$
D^{s}\left(p_{i}\right)=\frac{\alpha \cdot A}{n+2}-\left(p_{i}-\frac{2 A}{n+2}\right)=\frac{(\alpha+2) \cdot A}{n+2}-p_{i} .
$$

The profit function is

$$
\Pi_{i}=p_{i} \cdot q_{i}-q_{i}^{2}=\left(\frac{(\alpha+2) \cdot A}{n+2}-p_{i}\right) \cdot\left(2 p_{i}-\frac{(\alpha+2) \cdot A}{n+2}\right),
$$

which reaches its maximum at $p_{i}=\frac{3}{4} \cdot \frac{(\alpha+2) \cdot A}{n+2}$. This price exceeds $P^{*}=\frac{2 A}{n+2}$ precisely when $\frac{3}{4} \cdot(\alpha+2)>2$ or $\alpha>\frac{2}{3}$. This implies that the Bertrand equilibrium with $P^{*}=\frac{2 A}{n+2}$ and $q_{i}^{*}=\frac{A}{n+2}$, for all $i \in N$, remains an equilibrium as long as $\alpha \leq \frac{2}{3}$. The Bertrand equilibrium is destroyed when $\alpha>\frac{2}{3}$.

\section{Concluding Remarks}

Perhaps, one of the most well-known contributions to understanding the oligopoly problem is Kreps and Scheinkman (1983). They have shown that price competition conditional on choices of capacity may yield Cournot-like outcomes. This result assumes, among other things, that each firm has full knowledge about all output decisions before deciding on price. In this paper, we relaxed this requirement by considering games where firms pick prices and production levels simultaneously. As an interesting contrast, this may yield Bertrand-like outcomes. Additionally, there might exist equilibria in which firms serve only part of their clientele. The latter can occur when products are perfect substitutes and cost functions exhibit decreasing returns to scale.

Apart from the characterization of equilibria, our analysis also suggests that the non-existence problem may not be as severe as is commonly thought. In particular, the absence of a purestrategy equilibrium in price-quantity games is not primarily driven by the assumption that firms choose prices and quantities, but more by how cost and demand are modeled. Therefore, if we are to better understand how price is determined in oligopolies, our focus should not be on selecting the appropriate strategic variable. After all, in non-regulated markets firms almost always choose both prices and quantities. Instead, the aim should be to deepen our understanding of the foundations of cost and demand. We leave this issue for future research. 


\section{References}

[1] Alger, Daniel R. (1979), "Markets where Firms select both Prices and Quantities: an Essay on the Foundations of Microeconomic Theory," Doctoral Dissertation, Northwestern University;

[2] Benassy, Jean-Pascal (1989), "Market Size and Substitutability in Imperfect Competition: A Bertrand-Edgeworth-Chamberlin Model," Review of Economic Studies, 56(2), 217-234;

[3] Bertrand, Joseph (1883), "Théorie mathématique de la richesse sociale (review)," Journal des Savants, 499-508;

[4] Bowley, Arthur L. (1924), "The Mathematical Groundwork of Economics," Oxford University Press: Oxford;

[5] Canoy, Marcel (1996), "Product Differentiation in a Bertrand-Edgeworth Duopoly," Journal of Economic Theory, 70(1), 158-179;

[6] Cournot, Antoine-Augustin (1838), "Researches into the Mathematical Principles of the Theory of Wealth," Macmillan: New York (ed. Bacon; 1897);

[7] Dixon, Huw D. (1984), "The Existence of Mixed-Strategy Equilibria in a Price-Setting Oligopoly with Convex Costs," Economics Letters, 16(3-4), 205-212;

[8] Dixon, Huw D. (1990), "Bertrand-Edgeworth Equilibria when Firms Avoid Turning Customers Away," Journal of Industrial Economics, 39(2), 131-146;

[9] Dixon, Huw D. (1992), "The Competitive Outcome as the Equilibrium in an Edgeworthian Price-Quantity Model," Economic Journal, 102(411), 301-309;

[10] Edgeworth, Francis Y. (1922), "The Mathematical Economics of Professor Amoroso," Economic Journal, 32(127), 400-407;

[11] Edgeworth, Francis Y. (1925), "The Pure Theory of Monopoly," Papers Relating to Political Economy, 1, 111-142;

[12] Friedman, James W. (1988), "On the Strategic Importance of Prices versus Quantities," RAND Journal of Economics, 19(4), 607-622;

[13] Gertner, Robert H. (1986), "Essays in Theoretical Industrial Organization," Doctoral Dissertation, Massachusetts Institute of Technology; 
[14] Hotelling, Harold (1929), "Stability in Competition," Economic Journal, 39(153), 41-57;

[15] Khan, Abhimanyu and Ronald Peeters (2015), "Imitation by price and quantity setting firms in a differentiated market," Journal of Economic Dynamics 8 Control, 53, 28-36;

[16] Kreps, David M. and Jose A. Scheinkman (1983), "Quantity Precommitment and Bertrand Competition Yield Cournot Outcomes," Bell Journal of Economics, 14(2), 326-337;

[17] Levitan, Richard and Martin Shubik (1972), "Price Duopoly and Capacity Constraints," International Economic Review, 13(1), 111-122;

[18] Maskin, Eric (1986), "The Existence of Equilibrium with Price-Setting Firms," American Economic Review, 76(2), 382-386;

[19] Shapley, Lloyd S. and Martin Shubik (1969), "Price Strategy Oligopoly with Product Variation," Kyklos, 22(1), 30-43;

[20] Shubik, Martin (1955), "A Comparison of Treatments of a Duopoly Problem (Part II)," Econometrica, 23(4), 417-431;

[21] Shubik, Martin (1960), "Strategy and Market Structure: Competition, Oligopoly and the Theory of Games," John Wiley Sons, Inc.: New York;

[22] Tasnádi, Attila (1999), "Existence of pure strategy Nash equilibrium in BertrandEdgeworth oligopolies," Economics Letters, 63, 201-206;

[23] Tasnádi, Attila (2004), "Production in advance versus production to order," Journal of Economic Behavior \& Organization, 54(2), 191-204;

[24] Vives, Xavier (1999), "Oligopoly Pricing: Old Ideas and New Tools," The MIT Press: Cambridge, Massachusetts. 